\title{
Effects on Children's Health by Excessive Use of Online Devices: A Study from the Parents Perspectives
}

\author{
Amin Palikhe* \\ Nabin Bahadur Adhikari**
}

DOI: https://doi.org/10.3126/jnbs.v13i1.34709

\begin{abstract}
This paper aims to identify the patterns of excessive use of online devices by children and its physical and behavioural impact on children's health of five different age groups: 0-less than 3, 3-7, 7-10, 10- 13 and over 13years of age. A survey was conducted with 42 respondents by using an on-line Google form in Pokhara. The purposive sampling method was used to select the sample and an online questionnaire was used to accumulate data from the parents. The target sample groups are parents who have children with age below 14 years. It is not a surprising matter that children have become good operators of any online devices these days. Therefore, this research paper attempts to find out any relationships that exist between online device user children and physical problems that they suffer. So a hypothesis has been developed to test whether "excessive online devices uses affects children's health?" A hypothesis was tested through Kendall's tau- $b\left(\tau_{b}\right)$ correlation coefficient, a non-parametric test. This paper concludes that the time is managed by the parent to their children for the use of the internet. Due to this effort of the parents, there is no serious physical health problem arising in the children and the parents are also not worried about their excessive engagement on electronic gadgets.
\end{abstract}

Keyword: Children, health, internet, parent, perspective

\footnotetext{
* Mr. Palikhe is an Assistant Professor at Faculty of Management, Prithvi Narayan Campus, Tribhuvan University.

** Mr. Adhikari is an Assistant Professor at Faculty of Management, Prithvi Narayan Campus, Tribhuvan University.

Corresponding Authors: Mr. Amin Palikhe. Email: a2shrestha@gmil.com
} 


\section{INTRODUCTION}

Modern life cannot be imagined without the use of the internet. People of all ages are now bound to use the internet for information, communication, education, business, entertainment, etc. Recently the use of the internet has become very popular among children as well. Although there is a debate going on whether the use of online devices be controlled or encouraged for children, the use of the internet among children has already been a daily habit for the easy access of digital devices like smartphones, computers and other electronic gadgets. The interests in using online among different age groups of children may vary regarding the choice of stuff available on the internet. The common interests that every child shows nowadays are Youtubing and Facebooking. Moreover, an online video game is a new addition to the online use of children which has become an addiction among them (Nasmita, Jannat, Chowdhury, \& Hasan, 2020).

Internet is necessary for everyone in all walks of modern life. It has positive and negative effects but it requires handling and using properly. It makes children busy by using smartphones and the internet but the question is whether it is safe for children or not. They can be the victims of online violence, cyberbullying, digital harassment, sexual exploitation and sexual abuse.

Nowadays, the internet is becoming an integral part of the daily life of the children and teenagers who are the most users of the internet at home or school on a large scale. They are the first to begin experiencing problems associated with spending ever-increasing periods on the internet. That causes the risk of developing misuse that referred to in research literature as overuse of internet, problematical internet use and the maladaptive use of the internet. It is a recent and fast-growing clinical phenomenon that may enhance psychiatric and psychosomatic symptoms of those age group (Tsisika, Critselis, \& Louizou, 2011). The other risk factor was widespread internet access that facilitates their use of favorite applications whenever and wherever they want, which increase the negative consequences neither in psychiatric as internet addiction or psychosomatic as musculoskeletal discomfort, such as back, neck, shoulder, and limb pain (Jacobs, Hudak, \& McGiffert, 2009).

The Center of Health Protection of the Department of Health (CHPDH) summarized the negative effects of excessive use of the internet and electronic devices on teenagers' health and development from the physical aspect as obesity, decreasing physical fitness, vision problems, musculoskeletal problems, sleep deprivation, injury and accidents or in psychosocial aspect as poor academic performance, worsening family relations, increasing sense of loneliness, depression, lowing self-steam and other mental health problems (Department of Health, 2015). Many researchers found that excessive use of the internet may affect the physical health of the users and increase the risk of somatic health problems, being associated with insufficient sleep among female adolescents including children and excessive weight among male adolescents, increased head flexion and neck flexion, increased lumbar lordosis, also headache and musculoskeletal pain (Surisa, Akre, \& Pigueta, 2014). 
Among the internet and online devices user, children are one of them. Internet brings numerous benefits as well as immense risks for excessive internet user children. The online use of children has raised many questions regarding the children's welfare issue but in the context of Nepal, there are not legalized whether children use the internet or stay without use. In an era of technological advancement, a child easily gets acquainted with digital devices and becomes very skillful in using them at his early stage of physical, mental and psychological development. Internet addiction disorder (IAD) is now commonly seen among children who spend most of the time of the day and do not get engaged in physical movement or exercise. Intemperate and immoderate use of online by children create a lot of physical problems like - obesity, vision problem, sleep disorder, growth disorder and the EMF (electromagnetic fields) exposure, etc. More than 175,000 children go online for the first time every day and a new child every half second, tapping into great opportunities but facing grave risks (UNICEF, 2018).

Excessive online use is characterized by excessive or poorly controlled behaviors regarding computer use and internet access that lead to a problem for children's health who use the device for more than 6 hours a day, which was considered as excessive online use. Physical health problem is the condition of a body where the presence of disease or illness affects lifestyle, physical activity and behavior. This can happen when one gets addicted to excessive use of the internet. Therefore, this paper aims to explore the risk of physical health created by the children due to the use of excessive online devices from the perspective of parents.

Online safety for children in Nepal as well as around the world is one of the important issues that have been taken seriously for the betterment of the children's physical health and cognitive development. The excessive use of the internet always leads to physical health problems or disorders for the internet using children as they are liable to suffer from different types of physical problems as well as it affects physical development for the children in their early stage of life. Enough research should be conducted on this specific problem to discover the present situation and identify the risks that make children victim of online use by hampering their physical health. Thus, the main research question for the research paper is: Do excessive online uses affect children's physical health? Along with this, some sub-questions arise: In which types of activities children spend most of their time on online devices? Are there any physical problem present? What are the major physical problems that children have been facing due to online usage? What is the average time spent by children online? What are the remedies that parents follow to reduce excessive use of online devices? 


\section{LITERATURE REVIEW}

Nafee, Mohammed, and Al-Hamdan (2018) have shown that $86.6 \%$ of the Kingdom of Saudi Arabia (KSA) teenagers used the internet daily compared to $69.6 \%$ in the Arab Republic of Egypt (ARE). Regarding internet addiction, in teenagers, $0.9 \%$ were severe, $45.3 \%$ moderate and $47.7 \%$ mild compared to $0.3 \%, 46.3 \%$ and $44.2 \%$ in ARE, $67.3 \%$ of KSA teenagers have musculoskeletal pain with internet usage compared to $74.3 \%$ in ARE teenagers. No significant relation was found between both groups in relation to internet addiction. Significant relations were found in Saudi students' socio-demographic data and their level of internet addiction in the area of academic level $(\mathrm{p} \leq .001)$, and level of academic achievement $(p=.037)$. No significant relation was found in the same area for Egyptian students. The researchers suggest further studies to be conducted in this field on a larger sample size for both genders to identify the other factors related to excessive internet use.

Dishkova and Papancheva (2019) have published an article on New Trends and Issues Proceedings on Humanities and Social Sciences journal on the topic of digital skills and cyber addiction at primary school. This paper considers the problem of the Internet and more general cyber addiction of primary school children. Young children do not recognize the eagerness to take some digital device at hand as a problem. They cannot estimate the time spent on games or other online activities. A theoretical review of the problem was done, and the basic aspects of cyber addiction were mentioned. It was concluded that higher digital skills at an early age could be a factor for avoiding higher cyber addiction of the children.

Daramola (2015) distinguished two major dimensions in the internet parenting methods: that is a parental control and parental warmth. The methods differ when controlling for parent gender, educational background, and age appropriateness. Parenting methods are also seen to be connected significantly to the level of parent internet usage, internet attitude and internet experience. Parental methods have been found to contribute greatly to the child's internet usage. The highest internet level usage among the children is apparent when the parents approve a permissive parenting method; the lowest level is observed when the parent approves the controlled internet parenting method. The parents' internet behavior and parents' educational background greatly influence the internet usage of children at home and school. This thesis aimed to address a fundamental research question: What parents think about their children's internet use. The research design in this thesis involves a qualitative study in which a semi-structured interview was conducted in a comfortable and friendly environment. As a requirement, eleven children and five families were interviewed. The parents who were interviewed are well aware of their children's internet access and usage.

As increasing numbers of researchers from around the world are becoming interested in how children use the internet, mobile technologies and electronic gadgets, there is increasing global evidence of both the opportunities that the internet brings and their associated risks. Looking up with the past research on the use of online devices by children and their effect on their health, the theoretical framework can be developed in the following way. 

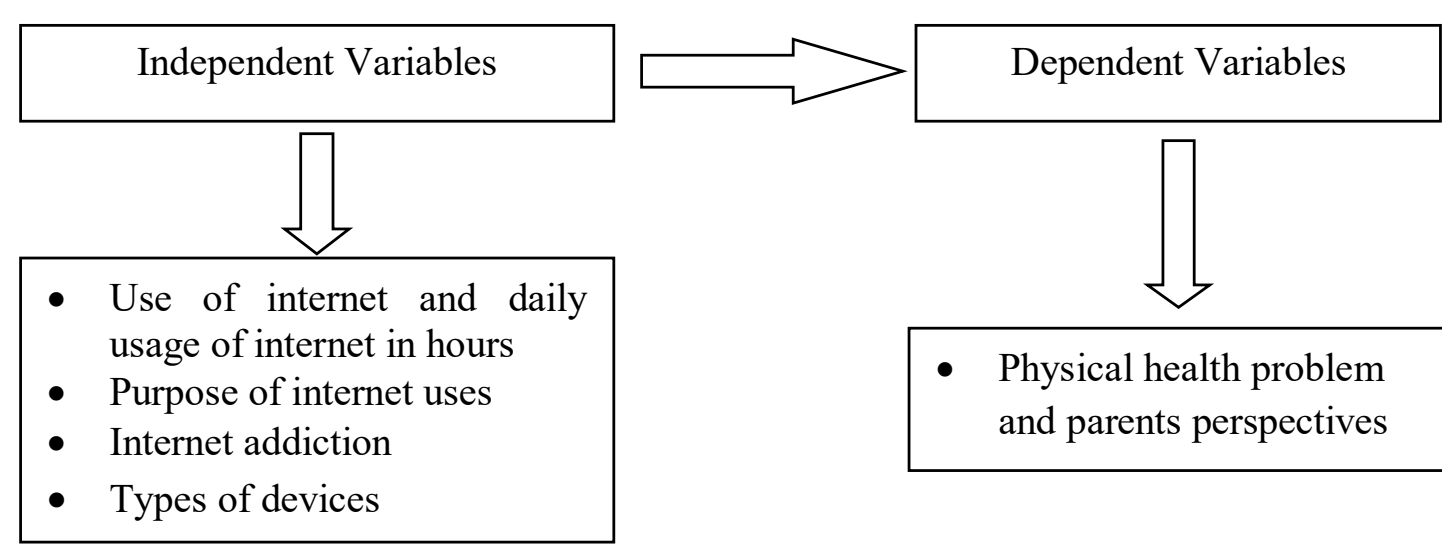

Figure 1. Theoretical framework.

\section{DATA AND METHODS}

This research is a fact-finding operation searching for adequate information. It is a type of research paper which is generally conducted to assess the opinions, behaviours, or characteristics of a given population and to describe the situation and events occurring at present. This paper highlights a process of accumulating facts so it is based on a descriptive and analytical research design. The online survey questionnaire had been developed and distributed to parents having children of the age below 14 years. The study employs primary sources of data, mainly the responses of respondents through a questionnaire. The actual target group of the population was children below the age of 14 years; but questionnaires were distributed online to the parents to know the exact problem and to obtain a rational answer of the survey of children using online devices therefore, this paper assumes that the population is the parents having children less than 14 years old. Altogether 42 samples had been taken through online. The online questionnaire contained 15 different questions. After the collection of the questionnaire from the parents, checking had been done to ensure that all parts were completed, and then it was coded. Data were organized, revised, stored, tabulated and analyzed, using descriptive and inferential statistics with Statistical Package for Social Sciences (SPSS). The questionnaire received from the online survey was tabulated and constructed a bi-variate table to analyse and test the hypothesis between the effect of excessive uses of online devices and physical health problems from parents' perspectives.

A hypothesis was developed and it was tested through Kendall's tau-b $\left(\tau_{\mathrm{b}}\right)$ correlation coefficient. Kendall's tau-b is a nonparametric measure of the strength and direction of association that exists between two variables measured on at least an ordinal scale. It is considered as a nonparametric test especially when the researcher has a small sample size and data. The two variables are excessive use of online gadgets and physical health problems and parents' perspective towards the use of online devices. The collected online data was further analysed with the help of IBM-SPSS program. Those scores and relationships have been 
presented in the form of a chart, percentage, and correlation. When analyzing, the missing data were excluded to present the real situation of the survey. The online questionnaire completion rate was about $75 \%$. The excessive use of online gadgets is the independent variable and physical health problem is the dependent variables. The consent has been taken from respondents. Researchers requested the respondents to answer on an online form with full details of the research objectives. A respondent had been given full right to withdraw certain responses if they wished to. The calculated value is drawn with the help of the following model:

$$
\operatorname{Kendall} \text { 's tau- } \mathrm{b}\left(\tau_{\mathrm{b}}\right)=\frac{N s-N d}{\sqrt{(\mathrm{Ns}+\mathrm{Nd}+\mathrm{Ty})(\mathrm{Ns}+\mathrm{Nd}+\mathrm{Tx})}}
$$

Where,

$\left(\tau_{\mathrm{b}}\right)=$ Kendall's tau-b $\left(\tau_{\mathrm{b}}\right)$ correlation coefficient

$\mathrm{Ns}=$ Total number of same ordered pairs

$\mathrm{Nd}=$ Total number of inverse ordered pairs

Ty $=$ Total number of tied dependent pairs

$\mathrm{Tx}=$ Total number of tied independent pairs

\section{RESULTS AND DISCUSSION}

The majority of parents have participated from the urban side than the rural side in the online survey. Urban parents' involvement was $95 \%$ whereas the rest are from the rural side in the online survey.

Figure 2 shows that the number of children that the parents have. According to the online survey, $60 \%$ of parents have just a single child followed by $35 \%$ of two children and $5 \%$ of more than two children in their family.

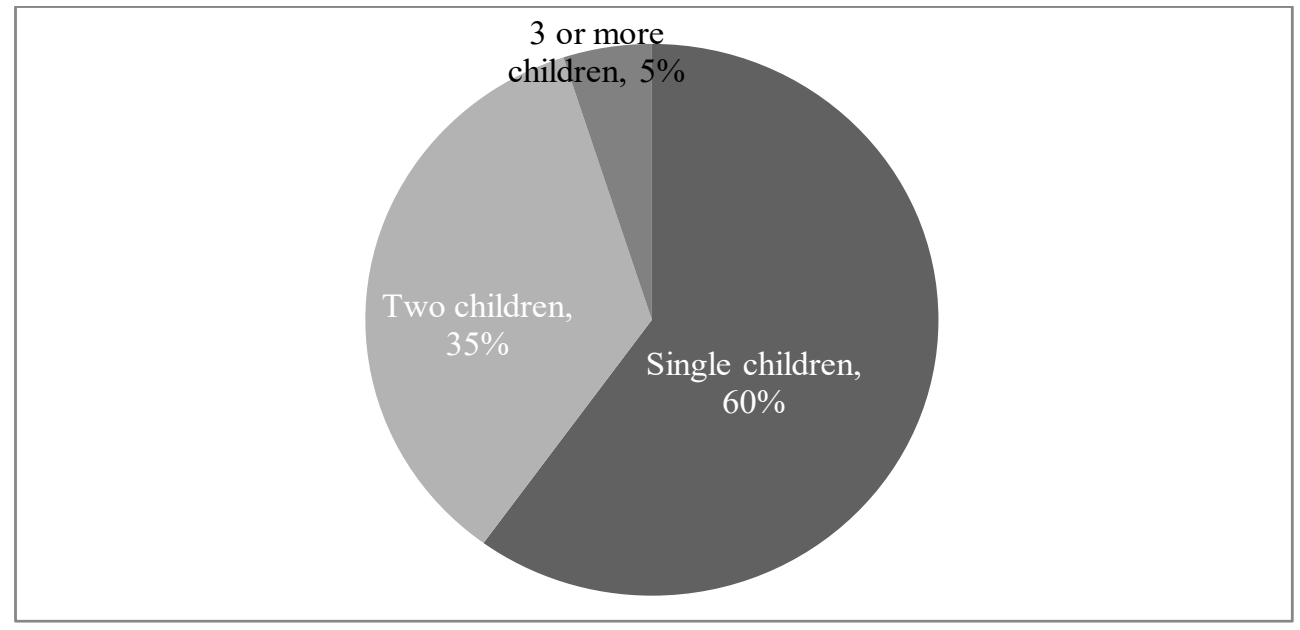

Figure 2. Distribution of the number of children of surveys' parent. 
Table 1

Appearance of Physical Problem and Average Hours of Use of Online Devices

\begin{tabular}{lccccc}
\hline \multirow{2}{*}{$\begin{array}{c}\text { Appearance of } \\
\text { physical problem }\end{array}$} & \multicolumn{5}{c}{ Average hours of use of online device (daily) } \\
\cline { 2 - 5 } & $0-3$ hours & $\begin{array}{c}4-6 \\
\text { hours }\end{array}$ & $7-9$ hours & 10 and more hour & Total \\
\hline Absent & 19 & 8 & 3 & 2 & $32(78 \%)$ \\
Present & 2 & 3 & 2 & 2 & $9(22 \%)$ \\
\hline Total & 21 & 11 & 5 & 4 & $41(100 \%)$ \\
\hline
\end{tabular}

Source: Online survey, 2020

Table 1 reveals that 78 percent of children still do not have any health problems though they use internet devices whereas 59.4 percent of children who have been using the internet for up to 3 hours are not facing health-related problems. Most of the children $(51.23 \%)$ use internet gadgets for less than three hours. Only $22 \%$ of parents believe that their children have physical problems due to the use of online devices.

To determine the relationship between two variables, to use Kendall's tau-b as a measure of association as it provides information on the existence direction and strength of the relationship. But precondition of applying Kendall's tau-b is that categories of the variable must be ranked ordered as high and low. For this purpose, daily usage of less than six hours is considered as low use and more than six hours is considered as high usage. Similarly, the presence of physical illness is considered as a high physical problem and the absence of illness is considered as a low physical problem (Daramola 2015).

Table 2

Degree of Physical Problem Present and Excessive Use of Online Devices

\begin{tabular}{lccc}
\hline & & \\
Degree of physical problem present & Use of online devices & Total \\
\cline { 2 - 3 } & & Low & \\
\hline High & 3 & 6 & 9 \\
Low & 6 & 22 & 28 \\
\hline Total & 30 & 9 & 39 \\
\hline Kendall's tau-b & & & 0.12 \\
\hline
\end{tabular}

Source: Online survey, 2020

Table 2 shows that the excessive online uses and physical health problem have a causal relationship. The strength of the relationship is weak and the direction of the relationship is positive. Hence the research hypothesis, the physical problems and excessive 
use of online devices are associated with each other is proved thereby with low effect on children's health in the Nepalese context.

Table 3

Data Related to Average Hours of Use of Online Devices by the Children

\begin{tabular}{|c|c|c|c|c|c|c|c|}
\hline \multirow[t]{2}{*}{ Age group } & \multicolumn{4}{|c|}{ Average hours of use of online device } & \multirow[t]{2}{*}{ Total } & \multirow{2}{*}{$\begin{array}{l}\text { Average hanging } \\
\text { time on online } \\
\text { (daily) }\end{array}$} & \multirow[t]{2}{*}{ Average time } \\
\hline & $\begin{array}{c}0-3 \\
\text { hours }\end{array}$ & 4-6 hours & $7-9$ hours & $\begin{array}{l}10 \text { and } \\
\text { more hour }\end{array}$ & & & \\
\hline Less than 3 & 6 & 0 & 0 & 1 & 7 & $3.5 \mathrm{hrs}$ & \\
\hline $3-7$ & 11 & 3 & 0 & 0 & 14 & $7 \mathrm{hrs}$ & \\
\hline $7-10$ & 3 & 1 & 3 & 2 & 9 & $2.25 \mathrm{hrs}$ & \\
\hline $10-13$ & 5 & 4 & 2 & 2 & 13 & $3.25 \mathrm{hrs}$ & $3.6 \mathrm{hrs}$ \\
\hline Above 13 & 2 & 4 & 1 & 1 & 8 & $2 \mathrm{hrs}$ & \\
\hline Total & 27 & 12 & 6 & 6 & 51 & & \\
\hline
\end{tabular}

Source: Online survey, 2020

Table 3 reveals that the average time for children using online devices is 3.6 hours daily whereas age group three to seven years kids has been spending their maximum time with online gadgets i.e.; average 7 hours daily. However, the age group of more than 13 years children has been with such devices averaged two hours daily. The time of hanging on electronic gadgets of children is lower than average except for the kids between 3-7 years.

Table 4

Timing of Operating Electronic Gadgets by Age Mix

\begin{tabular}{lccc}
\hline Age group & \multicolumn{2}{c}{ Time of gadgets use } & Total \\
\cline { 2 - 4 } & $\begin{array}{c}\text { Have a particular } \\
\text { time }\end{array}$ & $\begin{array}{c}\text { Do not have a particular } \\
\text { time }\end{array}$ & \\
\hline Less than 3 & 2 & 5 & 7 \\
$3-7$ & 5 & 10 & 15 \\
$7-10$ & 3 & 6 & 9 \\
$10-13$ & 3 & 10 & 8 \\
Above 13 & 3 & 5 & $52(100 \%)$ \\
\hline Total & $16(30.77 \%)$ & $36(69.23 \%)$ & 8 \\
\hline
\end{tabular}

Source: Online survey, 2020

Table 4 shows that the percentage of children who have a particular time when to use devices is 30.77 percentages whereas 69.23 percent of kids do not have any particular time to use electronic gadgets. Most of the children can use electronic gadgets whenever they want so they have autonomy about the timing of using devices. 


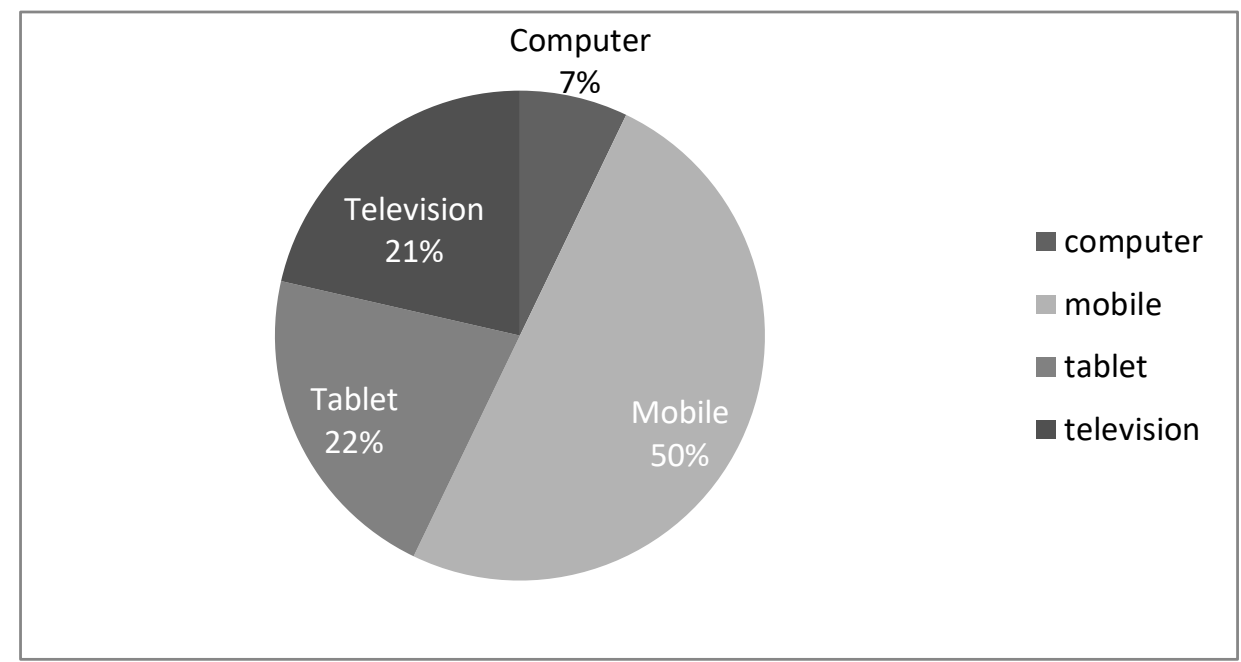

Figure 4. Pie chart showing the percentage of children who use particular devices.

Figure 4 demonstrates that maximum kids spend their time on mobile devices. Half $(50 \%)$ of the respondents said that their children spend time on mobile devices. The least percentage $(7 \%)$ of kids has been spending their time on using computers. The addictions of children are more on mobile rather than other devices.

Table 5

Holding of Device by Children on the Basis of Age Mix

\begin{tabular}{lccc}
\hline Age group & \multicolumn{2}{c}{ Holding of device } & Total \\
\cline { 2 - 3 } & Have & Do not have & \\
\hline Less than 3 & & 7 & 7 \\
$3-7$ & 4 & 11 & 15 \\
$7-10$ & 4 & 5 & 9 \\
$10-13$ & 7 & 6 & 13 \\
Above 13 & 4 & 4 & 8 \\
\hline Total & $19(36.53 \%)$ & $33(63.47 \%)$ & $52(100 \%)$ \\
\hline
\end{tabular}

Source: Online survey, 2020

Table 5 reveals that the percentage of kids who have their own device is 36.53percentage whereas 63.47 percentage of kids do not have their own. So, though most of the kids do not have their own device still they have an excess on electronic gadgets and become excessive users. 
Table 6

Time Spent on Using Particular Online Devices by Age Mix

\begin{tabular}{lllll}
\hline Age group & \multicolumn{2}{l}{ Number of children who engage in } & \multicolumn{2}{c}{ Total } \\
\cline { 2 - 4 } & Game & Social media & Youtube & \\
\hline Less than 3 & 1 & 2 & 4 & 7 \\
$3-7$ & 4 & 1 & 4 & 15 \\
$7-10$ & 4 & 2 & 4 & 9 \\
$10-13$ & 7 & 3 & 3 & 8 \\
Above 13 & 2 & $8(15.38 \%)$ & $26(50 \%)$ & $52(100 \%)$ \\
\hline Total & $18(34.6 \%)$ & & & \\
\hline
\end{tabular}

Source: Online survey, 2020

Table 6 indicates that $34.6 \%$ children spend their time on playing games on devices while $15.38 \%$ of children spend their time on social media and $50 \%$ of child spends their time on watching 'YouTube'. So, most of the children are like to watch YouTube than playing games and hanging on social media.

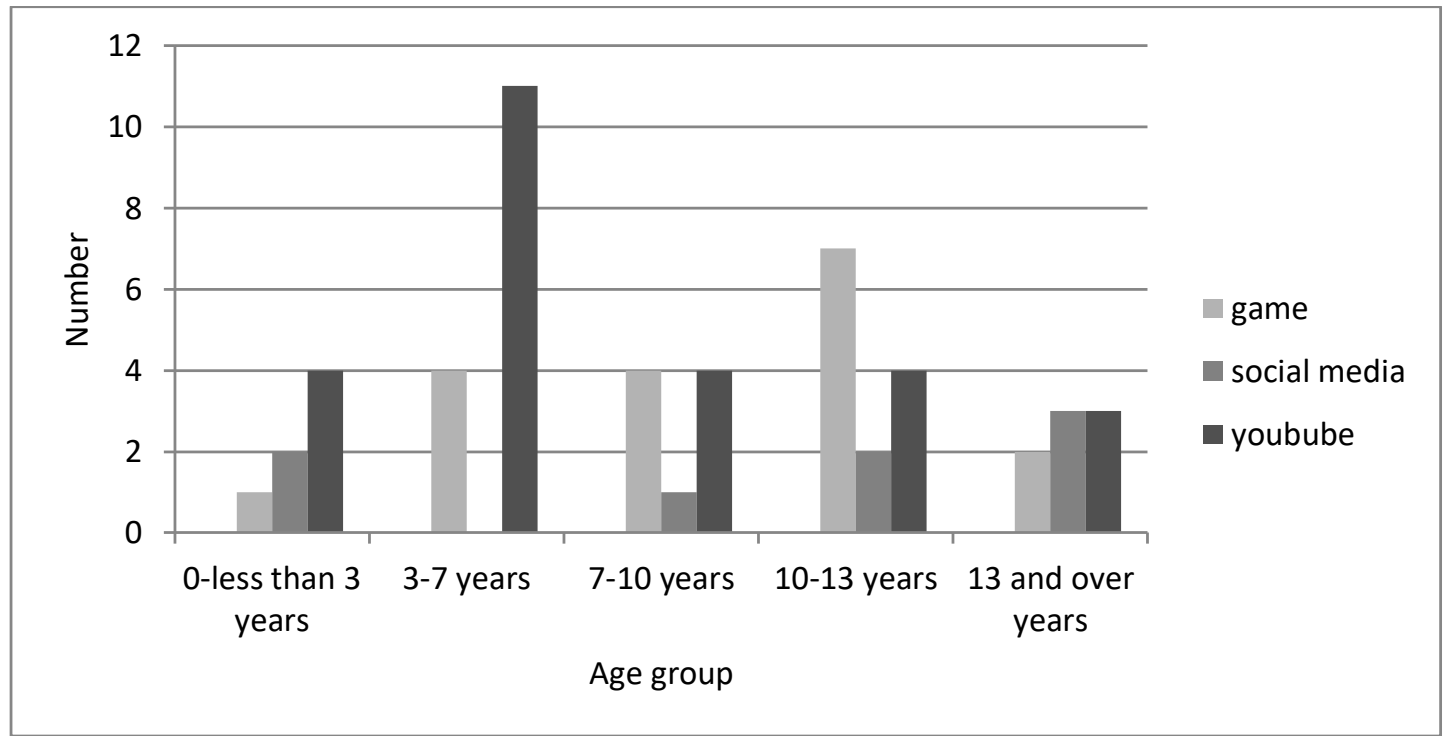

Figure 5. Distribution of the number of children.

Figure 5 shows that the age group of 3 to 7 years' children spends most of their time watching YouTube whereas they are not interested in social media and the age group of less than 3 years spends their minimum time on gaming. 


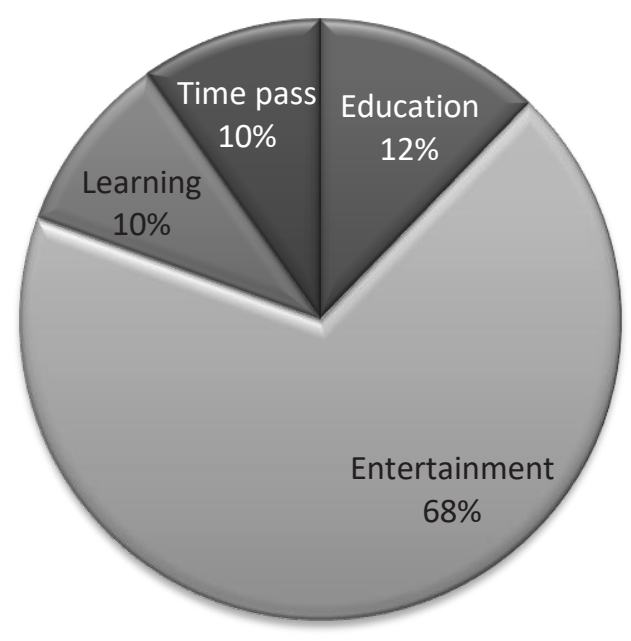

a education

$\square$ entertainment

- learning

a time pass

Figure 6. Percentage of distribution of the number of children involved in operating online devices.

Figure 6 shows that a maximum (68\%) of children use online devices for entertainment purposes than other purposes. It is found that the intention of least percentage of children to use electronic devices is for learning and time pass. The present-day parents easily allow their children to entertain online devices.

Table 7

Use of Device as a Problem

\begin{tabular}{lccc}
\hline Age group & \multicolumn{2}{c}{ Use of device as a problem } & \multirow{2}{*}{ Total } \\
\cline { 2 - 3 } & Yes & No & \\
\hline Less than 3 & 6 & 3 & 9 \\
$3-7$ & 12 & 3 & 15 \\
$7-10$ & 8 & 1 & 9 \\
$10-13$ & 8 & 3 & 11 \\
Above 13 & 4 & 4 & $52(100 \%)$ \\
\hline Total & $38(73.08 \%)$ & $14(26.92)$ & \\
\hline
\end{tabular}

Source: Online survey, 2020

Table 7 aims to explore the distribution of use of a device as a problem of using online devices by parents. From Table 7, it comes to know that 73.08 percent of parents consider online use as a problem while the rest $26.92 \%$ of parents do not think that is a problematic activity for their children. Parents who have children aged between 3 to 7 years perceived the using pattern of devices by their children as most problematic. 
Table 8

Data Related to the Presence of Addiction of Devices

\begin{tabular}{lllcc}
\hline Age group & \multicolumn{2}{c}{ Presence on addiction } & Total \\
\cline { 2 - 4 } & Yes & No & Not sure & \\
\hline Less than 3 & 1 & 1 & 5 & 7 \\
$3-7$ & 3 & 2 & 9 & 14 \\
$7-10$ & 4 & 1 & 3 & 8 \\
$10-13$ & 6 & 1 & 6 & 13 \\
Above 13 & 2 & 2 & 3 & 7 \\
\hline Total & $16(32.65 \%)$ & $7(14.29 \%)$ & $26(53.06)$ & $49(100 \%)$ \\
\hline
\end{tabular}

Source: Online survey, 2020

Table 8 shows that out of the responses of the total, $32.65 \%$ of parents think that their children are addicted to the electronic gadgets while 14.26 percent parents think that their children are not addicted to those devices but more than half that is 53.06 percent parents are not sure whether their children are addicted to an electronic device or not. Most parents are not aware of the children's addiction to online gadgets.

Table 9

Presence of Physical Health Problem

\begin{tabular}{lcccrc}
\hline Age group & \multicolumn{2}{c}{ Presence of physical health problem } & Total \\
\cline { 2 - 5 } & Change in behavior & $\begin{array}{c}\text { Change in life } \\
\text { style }\end{array}$ & $\begin{array}{c}\text { Effect in } \\
\text { physical } \\
\text { activities }\end{array}$ & Loneliness & \\
\hline Less than 3 & 4 & 1 & 1 & 1 & 7 \\
$3-7$ & 12 & & 3 & 0 & 15 \\
$7-10$ & 4 & 2 & 1 & 2 & 9 \\
$10-13$ & 6 & 2 & 3 & 1 & 12 \\
Above 13 & 5 & 1 & 1 & 0 & 7 \\
\hline Total & $31(62 \%)$ & $6(12 \%)$ & $9(18 \%)$ & $4(8 \%)$ & $50(100)$ \\
\hline
\end{tabular}

Source: Online survey, 2020

Table 9 reveals that sixty-two percent of parents believed that the use of the devices caused to change in the behavior of their children while 12 percent of parents think that the lifestyle of children is changed due to the excessive use of online devices likewise 18 percent parents assumed that the use of electronic gadgets effect in the physical activities of their children and rest portion of respondents thought that their children feel loneliness by the constant use of these devices. All the parents have noticed certain health-related problems. 
Table 10

Remedies to Minimize Physical Health Problem

\begin{tabular}{|c|c|c|c|c|c|c|c|}
\hline \multirow{2}{*}{$\begin{array}{l}\text { Age } \\
\text { group }\end{array}$} & \multicolumn{6}{|c|}{ Remedies to minimize physical health problem } & \multirow[t]{2}{*}{ Total } \\
\hline & $\begin{array}{l}\text { Give fix time } \\
\text { to operate }\end{array}$ & $\begin{array}{l}\text { Refuse to } \\
\text { give device }\end{array}$ & $\begin{array}{l}\text { Talking with } \\
\text { children to } \\
\text { forget to use } \\
\text { device }\end{array}$ & $\begin{array}{c}\text { Going out } \\
\text { with children }\end{array}$ & $\begin{array}{l}\text { Put device } \\
\text { out of } \\
\text { reach of } \\
\text { children }\end{array}$ & $\begin{array}{l}\text { Give and } \\
\text { show an } \\
\text { example } \\
\text { of effect }\end{array}$ & \\
\hline $\begin{array}{l}\text { Less than } \\
3\end{array}$ & 4 & 0 & 2 & 0 & 0 & 0 & 6 \\
\hline $3-7$ & 7 & 0 & 1 & 0 & 2 & 0 & 10 \\
\hline $7-10$ & 3 & 1 & 1 & 3 & 0 & 0 & 8 \\
\hline $10-13$ & 4 & 0 & 0 & 1 & 0 & 0 & 5 \\
\hline Above 13 & 3 & 0 & 1 & 0 & 0 & 1 & 5 \\
\hline Total & $21(61.76 \%)$ & $1(2.94 \%)$ & $5(14.71 \%)$ & $4(11.76 \%)$ & $2(5.88 \%)$ & $1(2.94 \%)$ & $\begin{array}{l}34(100 \\
\text {. }\end{array}$ \\
\hline
\end{tabular}

Source: Online survey, 2020

Table 10 exposes the remedies to minimize physical/health problems of children from the parents' side. Most of the parents $(61.76 \%)$ have given priority to fix the time for their children to be involved in their devices whereas 2.94 percent each refuse to give the devices and provide the paradigm of the excessive use of these electronic gadgets.

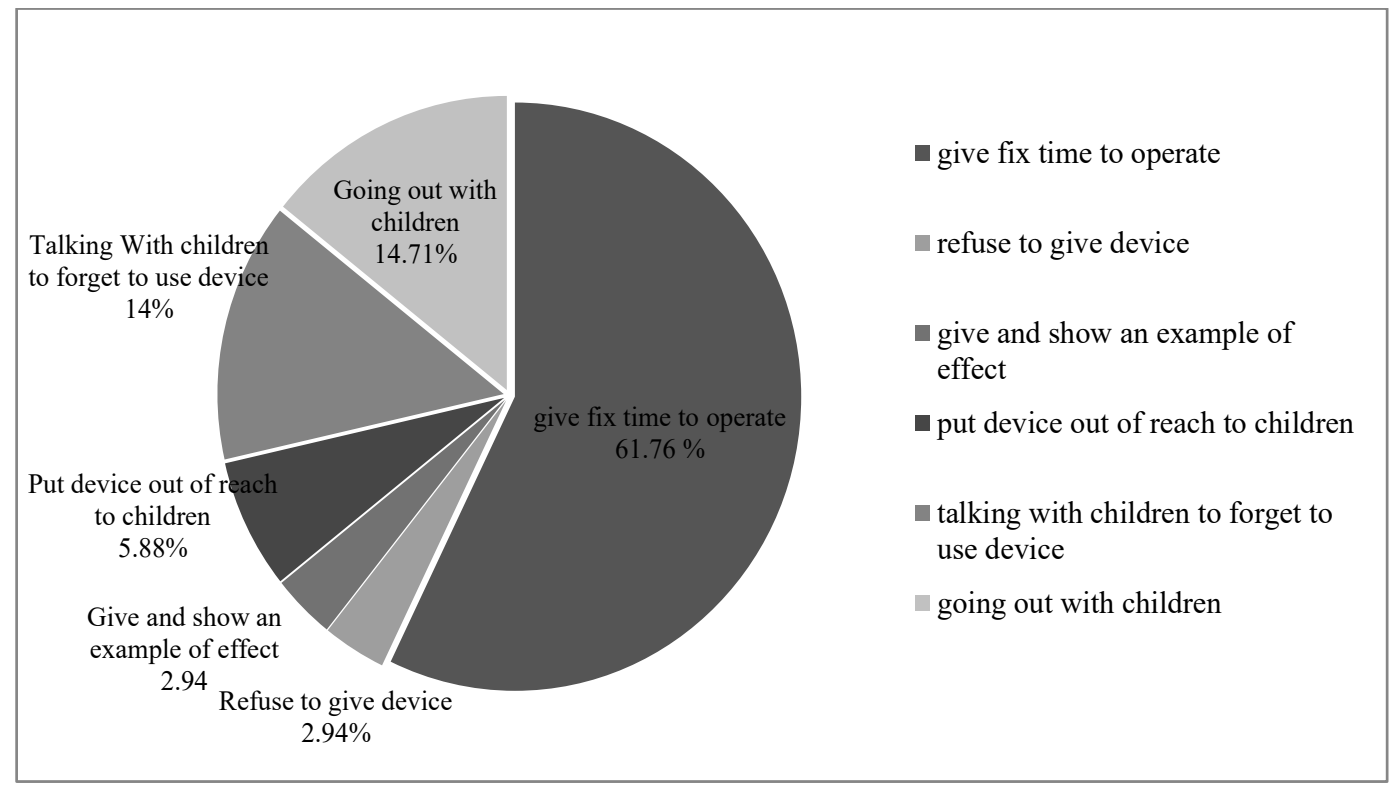

Figure 9. Distribution of minimizing the way of physical health problem from parents' perspective. 
Figure 9 show that $61.76 \%$ of parents have fixed the time for their children to use these gadgets to minimize physical health problems. About the same portion of responses are found to minimize the physical problems they are going out with children and chatting with their children to make them forget to use device i.e; $14 \%$. The proportion of parents who put devices out of reach of children is $5.88 \%$. Most of the children are obeying their parents.

\section{CONCLUSION}

The study has provided useful information about internet addiction of children from the parents' perspective and addresses this as an additional problem. Near to one-third of children are using Internet to the level of it being as a problem for parents and half of parents thought that their children are addicted to internet use. Entertainment is the main cause of the operation of an internet device. Those who allocate limited time to internet seem to have a less physical health problem. It is obvious that they have no particular time to operate an internet device. The rates for the use of internet gadgets are an average spending time of four hours by the children. Internet addiction has caused health and behavioral related problems in kids. More than half of the children have been showing their behavior change. So it is concluded that the excessive use of electronic gadgets or/and internet still has no strong effect on the health of children from the parents' perspective. Management of time for the use of the device is a must to minimize such problems therefore parents have fixed the time of internet uses for their children.

\section{REFERENCES}

Daramola, D. (2015). Young children as internet users and parents' perspectives (Unpublished master's thesis). Department of Information Processing Science, University of Oulu, Finland.

Department of Health. (2015). The Government of the Hong Kong special administrative region. Report of advisory group on health effects of use of internet and electronic screen products. Retrieved from https:/www.studenthealth.gov.hk/english/internet/ report/files/_report_wa.pdf

Dishkova, M., \& Papancheva, R. (2019). Digital skills and the cyber addiction at primary school. New Trends and Issues Proceedings on Humanities and Social Sciences, 6(2), 22-31. Retrieved from https://doi.org/10.18844/prosoc.v6i2.4279

Jacobs, K, Hudak, S., \& McGiffert, J. (2009). Computer-related posture and musculoskeletal discomfort in middle school students. Work. 32(3), 275-283. PMid:19369720. Retrieved from https://doi.org/10.3233/wor-2009-0826

Nafee, H., Mohammed, B., \& Al-Hamdan, A. (2018). Effect of excessive internet use in Saudi and Egyptian teenagers' health: Comparative study. Journal of Nursing Education and Practice, 8, 25-35. Retrieved from https://doi.org/10.5430/ jnep.v8n9p25 
Nasmita, N. R., Jannat, H., Chowdhury, A., \& Hasan, M. S. (2020). Online uses of children (Unpublished report on Department of Criminology). University of Dhaka, Bangladesh.

Surisa, J, Akre, C., \& Pigueta, C. (2014). Is internet use unhealthy? A cross sectional study of adolescent internet overuse. Swiss Medical Weekly. The European Journal of Medical Science, 144, 1-7. Retrieved from https://doi.org/10.4414/smw.2014.14061

Tsisika, A, Critselis, E., \& Louizou, A. (2011). Determinants of internet addiction among adolescents: A case-control study. The Scientific World Journal, 11, 866-874.

UNICEF (2018 February 6). More than 17500 children go online for the first time every day. Press Release. Retrieved from: https:/www.unicef.org/bangladesh/en/pressreleases/more-than-17500-children-go-online-for-first-time-every-day-tapping-greatopportunities 